\title{
Neddle Percutaneous Fasciotomy in Treatment of Several and Advanced Cases of Dupuytren's Disease
}

\author{
*Federico Amadei \\ Orthopaedics Department, Hand Surgery Center, Italy \\ Submission: September 11, 2016; Published: September 23, 2016 \\ *Corresponding author: Federico Amadei, Hand Surgery Center, Orthopaedics Department, via einstein 23 Legnano (MI), Milano, Italy
}

\begin{abstract}
Dupuytren's disease is a common condition. Percutaneous needle fasciotomy it is a simple method that uses a hypodermic needle and is usually performed under local anesthesia. It has few complications and allows almost immediate return to work with few restrictions. It can provide complete deformity correction and may offer a long-term solution.

On this study we analyse the use of this technique in Dupuytren disease stade 3-4 Tubiana classification.

In conclusions percutaneous needle fasciotomy also in several and advanced cases of Dupuytren's disease is a simple, safety and reliable technique with few complications and low health and social costs.
\end{abstract}

Keywords: Dupuytren's disease; Percutaneous needle fasciotomy.

\section{Introduction}

Dupuytren's disease is a chronic fibrotising disorder consisting of pathologic production and deposition of collagen in the palmar fascia of the hand. The cause of Dupuytren's disease is largely unknown but a family history is often present. Additional risk factors include use of anti-epileptics drugs, alcolich over use, diabetes and hyperlipidaemia. Traditional management are fasciotomy, limited fasciectomy, total fasciectomy and dermofasciectomy, recently was introduced the use of collagenase.

Percutaneous fasciotomy has long been established as a treatment for Dupuytren's disease, was for the first performed by Cline in 1787 and also Sir Dupuytren's describe this technique for selected cases in '800 century. On 1993 it was reintroduced by the French rheumatologists Lermusiaux and Badois. The fasciotomy is the simple interruption and rupture of palmar or palmodigital cords and contractures.

\section{Materials and Methods}

This research study was designed and approved in 2015. From 1995 to 1998 we are treated 40 patients, selected with these criteria: aged ( $>65$ years), diabetics, hypertension and dialysis. We are treated cases with only one cord, rarely two, in some patients the fasciotomy are do it like first operating time followed by radical surgical aponevrectomy. We are treated only cases stade 1-2-3 following Tubiana classification.

After 2000 we start to treat also several and advanced cases, grade 3-4 according with Tubiana classification, and until 2008
20 cases are operated. All patients were reviewed with a mean follow up of 4 years, the functional and aesthetic results are good, no secondary complications were noted, in two cases a second operation were necessary for improve the results of the first time.

Patients were assessed postoperatively after 1 day, after 1, 4, and 8 weeks, and after 6 and 12 months.

A 15 or 17 gauge hypodermic needle is inserted through the skin and the dermis. The cords must be held under tension to pull the cord up and away from the deeper structures.

The process may be repeated if necessary, from proximal to distal, if there is still cord causing a residual contracture. To avoid tendon damage the patient is intermittently asked to actively flex and extend the digit to demonstrate the presence or absence of needle motion with active tendon excursion. If the needle moves with the finger it suggests inadvertent entry into the flexor tendon sheath and the needle should be repositioned. Skin tears may occur which may need bandaging until they heal. In our series was present in $10 \%$ of patients treated. Other complications include nerve injury and flexor tendon injury, which are both rare in litterature and absent in our series.

In literature permanent nerve injury and flexor tendon ruptures have been reported on the Tubiana series $0.2 \%$ and on Foucher publications $0.05 \%$. Van Rijssen performed a prospective randomised controlled trial comparing percutaneous needle fasciotomy and limited open fasciectomy in 117 hands. For 
Tubiana stages 1 and 2 percutaneous fasciotomy was equal to limited fasciectomy in efficacy and for Tubiana stage 3 and 4 disease limited fasciectomy was superior. Limited fasciectomy was, however, associated with a 5\% major complication rate, compared to zero major complications in the needle fasciotomy group. Badois reported on a multi-centre study involving 952 hands in 799 patients. A total of 3736 needle fasciotomies were performed. An improvement in more $71.2 \%$ of stage 3 cases and in $56.6 \%$ of stage 4 .

\section{Conclusion}

Percutaneous needle fasciotomy has been shown to be beneficial in Dupuytren's disease and the short-term structural efficacy is well documented. It is a simple and quick method, with a short sick leave period for the patient, limited care requirements and a low overall cost.

Recurrence rates are higher but major complications are avoided and the procedure can be repeated multiple times. Also in patients with Tubiana stage 3 or 4 can be used with satisfactory results. Percutaneous needle fasciotomy also in advanced cases of Dupuytren disease has lower, less serious, complication rates.

Most patients recover rapidly, the procedure is performed under local anaesthesia, in day surgery recovery.

It has a similar short-term outcome and higher initial satisfaction among patients compared to open procedures and clostridum hystoliticum use.

There is a significant cost saving compared to formal surgical procedures and to collagenase injection.
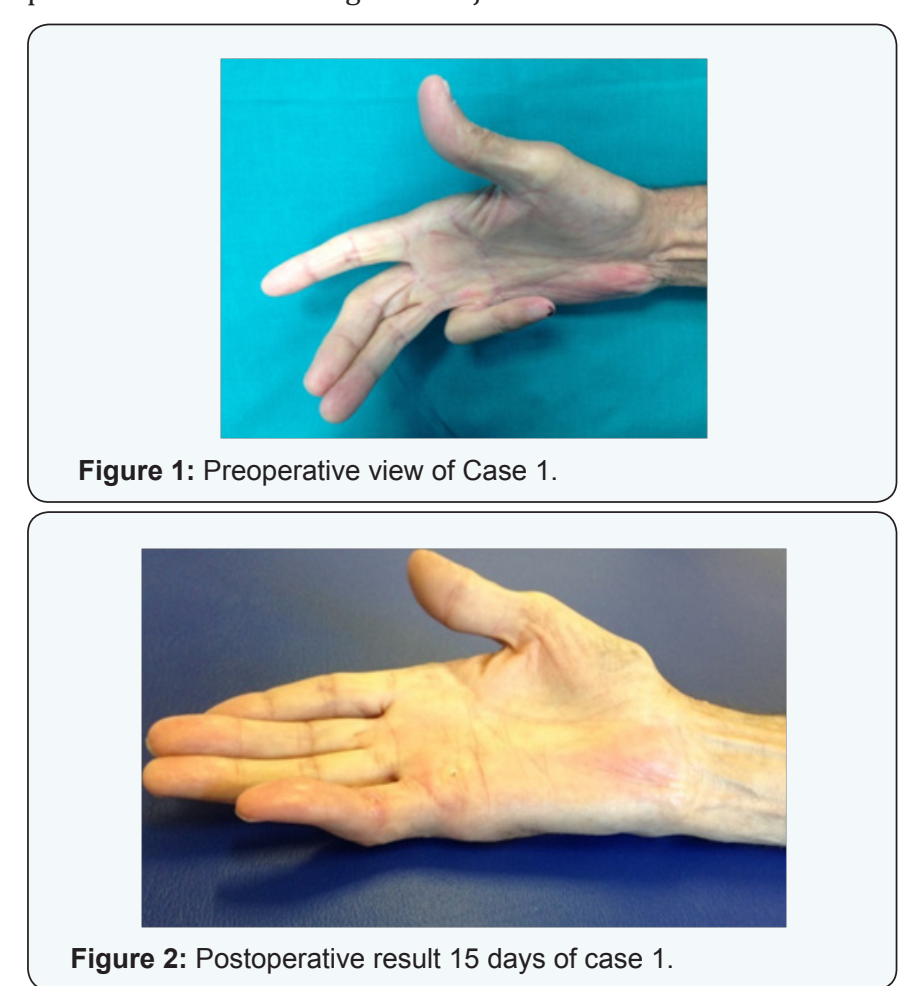


Percutaneous needle fasciotomy is an alternative treatment for Dupuytren's contracture also in advanced and several cases (Figures 1-4) compared with collagenase use and open partial fasciectomy [1-19].

\section{References}

1. Nagay B (1973) Closed fasciotomy (aponeurotomy) in treatment of Dupuytren's contracture. Chir Narzadow Ruchu Ortop Pol 38(5): 603606.

2. Badois FJ, Lermusiaux JL, Masse C, Kuntz D (1993) Non-surgical treatment of Dupuytren disease using needle fasciotomy. Rev Rhum Ed Fr 60(11): 808-813.

3. Lermusiaux JL, Badois F, Lellouche H (1983) Dupuytren's Disease. Rev Rhum 68: 542-547.

4. Colville J (1983) Dupuytren's contracture--the role of fasciotomy. Hand 15(2): 162-166.

5. Cheng HS, Hung LK, Tse WL (2008) Needle aponeurotomy for Dupuytren's contracture. J Orthop Surg 16(1): 88-90.

6. Bryan AS, Ghorbal MS (1998) "The long-term results of closed palmar fasciotomy in the management of Dupuytren's contracture". J Hand Surg 13(3): 254-256.

7. Tonkin MA, Burke FD, Varian JP (1984) Dupuytren's contracture: a comparative study of fasciectomy and dermofasciectomy in one hundred patients. J Hand Surg Br 9(2): 156-162.

8. Eaton C (2011) Percutaneous fasciotomy for Dupuytren contracture. J Hand Surg Am 36(5): 910-915.

9. Mc Millan C, Binhammer P (2012) Steroid injection and needle aponeurotomy for Dupuytren contracture: a randomized, controlled study. J Hand Surg Am 37(7): 1307-1312.

10. Beaudreuil J, Lermusiaux JL, Teyssedou JP (2011) Multi-needle aponeurotomy for advanced Dupuytren's disease: preliminary results 
of safety and efficacy (MNA 1 study). Joint Bone Spine 78(6): 625-628.

11. Foucher G, Medina J, Navarro R (2003) Percutaneous needle aponeurotomy: complications and results. J Hand Surg Br 28(5): 427431.

12. Pess GM, Pess RM, Pess RA (2012) Results of needle aponeurotomy for Dupuytren contracture in over 1,000 fingers. J Hand Surg Am 37(4): 651-656.

13. Van Rijssen AL, ter Linden H, Werker PM (2012) Five-year results of a randomized clinical trial on treatment in Dupuytren's disease: percutaneous needle fasciotomy versus limited fasciectomy. Plast Reconstr Surg 129(2): 469-477.

14. Van Rijssen AL, Werker PM (2006) Percutaneous needle fasciotomy in dupuytren's disease. J Hand Surg Br 31(5): 498-501.

15. Van Rijssen AL, Gerbrandy FS, Ter Linden H (2006) A comparison of the direct outcomes of percutaneous needle fasciotomy and limited fasciectomy for Dupuytren's disease: a 6-week follow-up study. J Hand Surg Am 31(5): 717-725.

16. Foucher Medina GJ, Malizos K (2001) Percutaneous needle fasciotomy in dupuytren disease. Tech Hand Up Extrem Surg 5(3): 161-164.

17. Pereira A, Massada M, Sousa R (2012) Percutaneous needle fasciotomy in Dupuytren's contracture: is it a viable technique. Acta Orthop Belg 78(1): 30-34.

18. Saffar P, Amadio PC, Faucher G, Saffar AP, Foucher G, et al. (1997) Treatment of Dupuytren's disease by percutaneous needle fasciotomy, Current Practice in Hand Surgery, London, UK, pp. 187-93.

19. Chen NC, Shauver MJ, Chung KC (2011) Cost-effectiveness of open partial fasciectomy, needle aponeurotomy, and collagenase injection for Dupuytren contracture. J Hand Surg Am 36(11): 1826.e32-1834. e32.

Your next submission with JuniperPublishers will reach you the below assets

- Quality Editorial service

- Swift Peer Review

- Reprints availability

- E-prints Service

- Manuscript Podcast for convenient understanding

- Global attainment for your research

- Manuscript accessibility in different formats ( Pdf, E-pub, Full Text, audio)

- Unceasing customer service

Track the below URL for one-step submission http://juniperpublishers.com/online-submission.php 